\title{
Ependymin as a Substrate for Outgrowth of Axons from Cultured Explants of Goldfish Retina
}

\author{
John T. Schmidt, ${ }^{1 *}$ Rupert Schmidt, ${ }^{2}$ Weichun Lin, ${ }^{1}$ \\ Xiaoying Jian, ${ }^{1}$ and Claudia A. O. Stuermer ${ }^{3}$ \\ ${ }^{1}$ Department of Biological Science and Neurobiology Research Center, State University of New York \\ at Albany, New York 12222; 'Zoology Dept. J.W. Goethe University, D-6000 Frankfurt am Main, FRG; \\ and ${ }^{3}$ Friedrich Miescher Lab., Max-Planck Institut, D-7400 Tuebingen, FRG
}

\section{SUMMARY}

Ependymin, a prominent protein of the brain's extracellular fluid (ECF) was previously implicated in the consolidation of memory and in the activity-driven sharpening of the retinotectal projection. Because both these phenomena probably involve the growth and elaboration of appropriate synapses, we have tested whether ependymin can serve as a substrate for the growth of axons from goldfish retinal ganglion cells in a culture assay. Ependymin (Ep), laminin (LAM), polylysine (PL), and Concanavalin A (Con A) were plated on glass coverslips either uniformly or in striped patterns. Ep alone, either soluble or partly polymerized (by dropping calcium concentration and $\mathrm{pH}$ ), was a good substrate for axonal outgrowth, as good or better than PL and Con $\mathrm{A}$, but not as good as LAM. Neurites grew faster on LAM $(71 \mu \mathrm{m} / \mathrm{h})$ than on $\operatorname{Ep}(32 \mu \mathrm{m} / \mathrm{h})$ or on $\operatorname{PL}(22 \mu \mathrm{m} / \mathrm{h})$.
Fasciculation was low on LAM, intermediate on Ep, and highest on PL. In exclusive side-by-side stripe assays, axons preferred LAM over Ep, but gave weak or no preference for Ep over Con A or PL. With stripes of LAM + Ep alongside pure LAM, the axons preferred the mixture of LAM + Ep. When antibodies to Ep were plated in stripes over continuous Ep substrate, the axons avoided the antibody-blocked stripes and grew on the Ep stripes. Antibodies to Ep did not, however, block growth on laminin substrates, nor did antibodies to LAM block growth on Ep. Dot blots and western blots showed very little cross recognition between the antibodies. Ependymin is a good substrate for neurite outgrowth, which is normally present in ECF, and adhesion to Ep is independent of LAM and possibly additive to it.

\section{INTRODUCTION}

Long-term memory requires protein synthesis (Flexner, Flexner and Stellar, 1963; Goelet, Castellucci, Schacher, and Kandel, 1986; Montarolo et al., 1986), and may involve growth and elaboration of the synapses participating in learning (Greenough and Bailey, 1988; Bailey and Chen, 1988). Recently, attention has turned to specific proteins that may be involved both in the consolidation of memory and in experience-dependent

Received June 13, 1990; accepted August 21, 1990

* To whom correspondence should be addressed. development where similar synaptic changes occur. One such protein, ependymin (Ep), has been implicated in the consolidation of memory in goldfish and mice (Shashoua, 1985; Schmidt, 1986) and in activity-driven retinotopic sharpening of the regenerating retinotectal projection of goldfish (Schmidt and Shashoua, 1988).

Ependymin has been localized by immunohistochemical staining within the ependymal glia (Benowitz and Shashoua, 1977; Schmidt and Shashoua, 1988), the leptomeninx (Schmidt, 1983) and some neurons (Schmidt et al., 1986, 1990), and is continually secreted as a disulfide-linked dimer of two polypeptide chains ( 37 and $31 \mathrm{kD}$ ) into the brain extracellular fluid (ECF) (Schmidt and Shashoua, 1981; Shashoua, 1985). It was first identified by double-labelling methods as a glyco- 
protein whose turnover rate increased in the brains of goldfish that learned a new pattern of swimming (Shashoua, 1976; Schmidt, 1987). Subsequent studies showed that injections of ependymin antibodies into the fourth ventricle within $24 \mathrm{~h}$ after training could block subsequent recall (Shashoua and Moore, 1978; Schmidt, 1986; Piront and Schmidt, 1988), suggesting that the protein could be involved in some aspect of the process of consolidation of long-term memory. Similarly, chronic infusion of antibodies to ependymin blocked the sharpening of the retinotectal map (Schmidt and Shashoua, 1988).

Ependymin has been reported to undergo irreversible polymerization when the calcium concentration and pH both drop significantly (Shashoua, $1985,1988)$. Because sustained activity at convergent synapses can transiently lower local calcium concentrations by as much as $70 \%$ (Krnjevic, Morris, and Reiffenstein, 1982; Marciani, Louvel, and Heinemann, 1982; Morris, Ropert, and Shashoua, 1988), the resulting deposition of polymerized ependymin into a matrix (Shashoua and Hesse, 1985) could play a role in promoting increased growth or elaboration at the sites of the participating synapses (Shashoua, 1985).

If ependymin serves such a role, then it should interact with retinal axons to serve as a growthpromoting substrate for growth cones. Consistent with this, ependymin has been localized by immunohistochemical staining to the astrocytes of the goldfish's optic nerve (J. Schmidt, R. Schmidt, and S. Rother, unpublished data). In the present studies, we have tested the ability of ependymin to serve as a substrate for growth of axons from explants of goldfish retina, and made direct comparisons with other established substrates using a previously developed stripe assay. The results show that it is a good substrate for axonal outgrowth, as good as polylysine (PL) or concanavalin A (Con A) but not as good as laminin (LAM).

\section{METHODS}

\section{Explant and Culture of Retinal Strips}

Retinal explants were prepared as previously described in detail (Vielmetter and Stuermer, 1989). In brief, retinas were isolated from goldfish (Carassius auratus, 5-8 $\mathrm{cm}$ long) that had received an optic nerve cut 14 days previously, attached to a nylon filter support, and cut into strips $300 \mu \mathrm{m}$ wide on a Mcllwain tissue chopper. These strips were plated onto the substrates with the ganglion cell layer down, and incubated in L15 medium with $10 \%$ fetal calf serum and $0.4 \%$ methylcellulose in culture dishes at $22^{\circ} \mathrm{C}$.

\section{Staining with Rhodamine}

To stain axons with rhodamine (McKenna and Raper, 1988 ), we fixed cultures with $2 \%$ glutaraldehyde in phosphate-buffered saline (PBS) $(2 \mathrm{~h})$, washed in distilled water, dried at room temperature, and incubated for $10 \mathrm{~min}$ with a rhodamine isothiocyanate (RITC) solution ( $1 \mathrm{mg}$ in $10 \mu \mathrm{l}$ dimethyl sulfoxide, and $10 \mathrm{~mL}$ distilled water). Cultures were washed in $70 \%$ and $96 \%$ ethanol ( 1 min each) to remove excess RITC, dried at room temperature, embedded in Enthellan (Boehringer), and photographed either on a Zeiss Axiophot or on an Olympus BH2 microscope with epaxial illumination using appropriate filter sets.

\section{Antibody Staining}

Cultures were fixed first with methanol at $-20^{\circ} \mathrm{C}$ for 10 min, then with $2 \%$ formaldehyde in PBS ( $\mathrm{pH} 7.3$ ) for 10 min. They were washed five times in PBS with $0.5 \%$ bovine serum albumin (BSA), incubated in antibody to ependymin or normal rabbit serum (NRS) $(1 / 200$ in PBS with 1\% BSA) for $4 \mathrm{~h}$ to overnight, washed five times, incubated for $2 \mathrm{~h}$ with goat anti-rabbit IgG labelled with fluorescein, washed five times, and mounted on a slide with Mowiol medium (Hoechst).

\section{Ependymin Purification}

Ependymin was isolated from the ECF of the goldfish brain by the method of Schmidt and Shashoua (1981). Briefly, brains removed from 100 fish and extracted with gentle agitation for $30 \mathrm{~min}$ in ice-cold Tris [tris(hydroxymethyl)amino-methane] extraction buffer [ 50 $\mathrm{m} M$ Tris, pH 7.2, $86 \mathrm{~m} M \mathrm{NaCl}, 2.5 \mathrm{~m} M \mathrm{CaCl}_{2}$ to prevent polymerization, $1 \mathrm{~m} M$ glutathione (reduced form, Sigma)], and $0.3 \mathrm{~m} M$ TPCK ( $N$-tosyl-1-phenylalanine chloromethyl ketone, Sigma) as protease and esterase inhibitors (Shashoua and Holmquist, 1986). The extracts were filtered and centrifuged $(100,000 \mathrm{~g}$ for $60 \mathrm{~min}$ ) to remove particulate matter, bound to $8 \mathrm{~g}$ of Con A-Sepharose beads (Pharmacia) for $1 \mathrm{~h}$ at room temperature, washed extensively, eluted with $300 \mathrm{mM}$ alpha methyl mannoside, and concentrated at $1{ }^{\circ} \mathrm{C}$ by ultrafiltration (Amicon filter PM10) to achieve a final protein content of $1 \mathrm{mg} / \mathrm{mL}$. The resulting solution contains several microheterogeneous forms of the dimeric ependymin molecule (Schmidt et al., 1990) and less than $10 \%$ nonependymin proteins. Freshly prepared ependymin was used within $5 \mathrm{~h}$ or stored frozen at $-80^{\circ} \mathrm{C}$ until used. In some early experiments, the extradural fluid, which is a rich source of ependymin was removed by microcapillary tubing, and centrifuged. Similar results were obtained with all ependymin preparations. 


\section{Antiependymin Antiserum}

Antiserum was raised in rabbit against the glycosylated $37 \mathrm{kDa}$ ependymin monomer, purified by SDS-polyacrylamide gel electrophoresis (PAGE) (Schmidt and Shashoua, 1981). This antibody recognizes the monomer forms of ependymin (Schmidt and Shashoua, 1983; Koenigstorfer et al., 1989) which represent $1-10 \%$ of the physiological mixture of ependymin molecules, and it shows little recognition of the native disulfide-linked dimeric forms that are predominant in purified Ep (Schmidt and Shashoua, 1981). This antibody also prevents memory consolidation after operant vestibulomotor training (Schmidt, 1987) and classical shock-avoidance conditioning (Piront and R. Schmidt, 1988).

\section{Ependymin Polymerization}

Purified ependymin, $1 \mathrm{mg} / \mathrm{mL}$ stored at $4^{\circ} \mathrm{C}$, was treated with $10 \%$ volume of $250 \mathrm{~m} M$ EGTA [ethyleneglycol-bis ( $\beta$-amino-ethyl ether)- $N, N^{\prime}$-tetraacetic acid, $\mathrm{pH} 4.1]$ about $30 \mathrm{~min}$ before plating. The final $\mathrm{pH}$ of the mixture was approximately 5.2. Fluorescent-staining with antibody on coverslips showed some clumps of polymerized Ep (as shown previously by Shashoua, 1985), but soluble ependymin undoubtedly remained and plated onto the glass as well.

\section{Plating of Proteins}

Glass coverslips were cleaned in $\mathrm{HNO}_{3}$, rinsed in distilled water, dried, and sterilized under ultraviolet (UV) light. A drop $(100 \mu 1)$ of substrate solution was placed between two coverslips. They were incubated at $37^{\circ} \mathrm{C}$ for $2 \mathrm{~h}$ ( to allow binding to the glass), rinsed in PBS, and separated. Retinal strips were explanted onto the substrate-coated surfaces of the coverslips.

Striped substrates were prepared using a special silicon matrix made by F. Bonhoeffer (MPI, Tuebingen) who developed the technique (Vielmetter, Stolze, Henke-Fahle, Stuermer, and Bonhoeffer, 1986). In brief, the silicon matrix consists of parallel $50-\mu \mathrm{m}$ channels separated by $40-\mu \mathrm{m}$ bars (Walter, Kern-Veits, Huf, Stolze, and Bonhoeffer, 1987). The open parallel channels merge at either end into inlet and outlet channel systems. The matrix is placed onto a coverslip and a substrate solution is injected into the channels, allowing it to bind to the glass in the corresponding pattern. Before the matrix is removed, a concentrated hemoglobin solution is used to saturate all sites in the first stripes. After the matrix is removed, a second solution is then bound to the previously covered stripes. In some experiments, fluorescent beads were added to the hemoglobin solution to facilitate the recognition of the first stripes. The addition of each solution is followed by $2 \mathrm{~h}$ of incubation at $37^{\circ} \mathrm{C}$ and three rinses with PBS to remove unbound substrate molecules.

The term exclusive stripes refers to cases where completely different substrates were applied to stripes 1 and 2. In other experiments, the entire coverslip was pre- coated with one substrate solution and dried prior to placing the matrix onto it and plating a second protein in the channels of the matrix. In these latter experiments, stripe 1 contained the first and second substrates, whereas stripe 2 contained only the first substrate.

The concentrations of the substrate solutions in PBS were as follows: Laminin (EHS sarcoma, Sigma or Collaborative Research), $20 \mu \mathrm{g} / \mathrm{mL}$; Polylysine (Sigma), $200 \mu \mathrm{g} / \mathrm{mL}$; Concanavalin A (Serva), $1 \mathrm{mg} / \mathrm{mL}$ ); Hemoglobin (bovine, Serva), $4 \mathrm{mg} / \mathrm{mL}$ ); Ependymin (goldfish, purified as described above), I mg/mL (except as otherwise noted). The antibody to Lam was obtained from Collaborative Research (Waltham, MA).

Antibody-blocking experiments used the polyclonal Ep antiserum in two types of experiments. In the first, ependymin was first applied to the channels, incubated, and then followed by antiEp in various dilutions (1:1, 1:4, 1:10, and 1:100) and the hemoglobin FITC solution. After removal of the matrix, ependymin was applied, followed by normal rabbit serum in the same dilution as the antiserum so that these components would be present in both stripes. In the second type of experiment, the entire coverslip was precoated with ependy$\min (0.1 \mathrm{mg} / \mathrm{mL}$ in PBS) and dried before the matrix was used to apply antiEp in stripes. After removal of the matrix, normal rabbit serum was applied in the same dilutions as the antiEp.

\section{Immunoblotting}

One dimensional SDS-PAGE was carried out on slab gels (Laemmli, 1970) using 7.5\% acrylämide for resolving gels and $5 \%$ for stacking gels. Samples were solubilized in Laemmli (1970) sample buffer with $5 \%$ betamercaptoethanol, loaded, and run overnight at $60 \mathrm{~V}$ followed by $200 \mathrm{~V}$ for $1 \mathrm{~h}$. Proteins were transferred to nitrocellulose paper $(0.2 \mu \mathrm{m})$ in a Hoeffer transphor apparatus using the procedure of Towbin, Staehelin, and Gordon (1979). The paper was blocked with 5\% BSA and incubated overnight in antibody at 1:500 (for both antiEp and antiLAM). The vectastain procedure (Vector Labs) was used to detect the rabbit antibodies with diaminobenzidine as chromogen. Gels were stained with Coomassie Blue R250 to check for completeness of transfer. Dot blots were applied to nitrocellulose paper in a BioRad apparatus according to their procedure except that the paper was removed, blocked with 5\% BSA, and processed free-floating along with the western blots.

\section{RESULTS}

\section{Ependymin as Substrate}

Ependymin was plated successfully onto glass and proved to be a good substrate for retinal axon outgrowth, slightly better than polylysine or Concanavalin A but not as good as laminin. These conclusions are based on more than 100 cultures each 


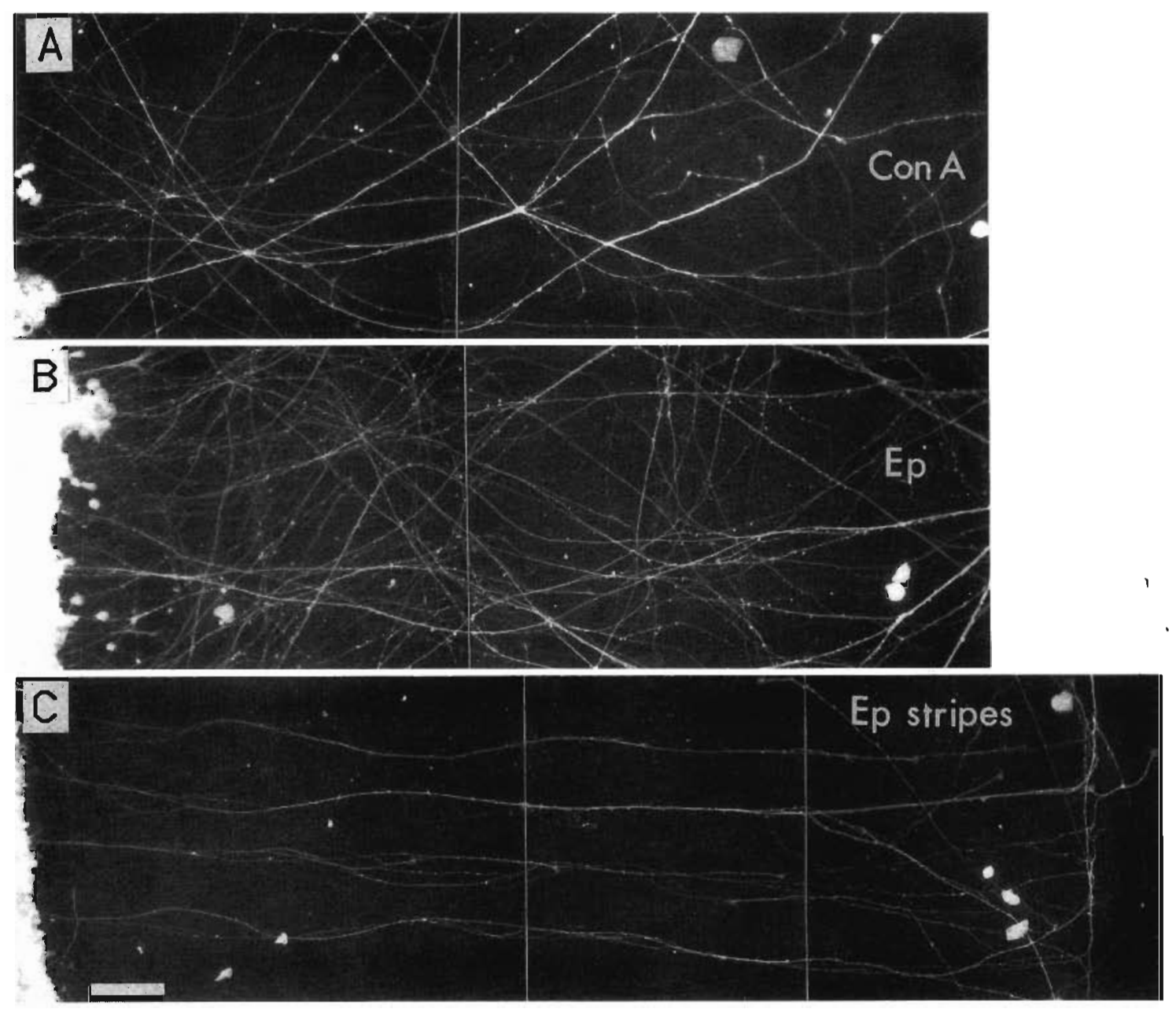

Figure 1 Outgrowth of axons on different substrates 2 days after explanting. (A) Uniform Con A on glass. (B) Uniform soluble ependymin on glass. (C) Polymerized ependymin stripes on glass. The retinal explant is at the left edge of each picture. The cultures were stained with rhodamine and viewed with epaxial fluorescence optics (Olympus, green excitation). Scale bar $=100 \mu \mathrm{m}$.

on Ep and LAM, 48 cultures on PL, 4 cultures on Con $\mathrm{A}$, and 44 cultures on uncoated glass. On ependymin substrates, many axons had grown out by 1 day, and by 2 days the axons had extended outward more than $1 \mathrm{~mm}$ in a dense mesh [Fig. $1(\mathrm{~B})]$. This outgrowth was at least as strong as that observed with Con A [Fig. 1 (A)] or PL [Fig. $2(\mathrm{~A})]$ as substrate. The rate of outgrowth on Ep was not as rapid as on laminin (LAM), however. During the first 2 days, outgrowing axons were longer on LAM substrates than on Ep in sister cultures. Quantification of growth rates of actively growing neurites that were made from photographs taken at hourly intervals (3-5 h during the first 2 days) showed this to be due to a slower average rate of growth on ependymin. Neurites on Ep grew at an average rate of $32 \mu \mathrm{m} / \mathrm{h}$ ( 1.7 S.E.M., $n=43$ ), whereas those on LAM grew at $71 \mu \mathrm{m} / \mathrm{h}$ (4.6 S.E.M., $n=61$ ). On PL, neurites grew slightly slower than on $\operatorname{Ep}(22 \mu \mathrm{m} / \mathrm{h}, 1.1$ S.E.M., $n=33)$. Neurites sustaining these rates would reach 1.7 $\mathrm{mm} /$ day on LAM, $0.75 \mathrm{~mm} /$ day on Ep, and 0.53 $\mathrm{mm} /$ day on PL. Because the longest growth usually exceeded $1 \mathrm{~mm}$ by 1 day on LAM and by 2 days on Ep and PL, the neurites were often growing at these rates. The maximum rates of growth also showed these differences between substrates. The fastest hourly rates observed on Ep and PL were 65 and $48 \mu \mathrm{m} / \mathrm{h}$, whereas the fastest on LAM was $238 \mu \mathrm{m} / \mathrm{h}$.

The pattern of growth on Ep and LAM also differed. On LAM, very little fasciculation occurred [Fig. 6(A)], whereas fasciculation was fairly common on Ep [Fig. 1(B), 6(B)]. In degree 
of fasciculation, growth on Ep was intermediate between that on LAM and that on PL [Fig. 2(A)] or Con A [Fig. 1(A)], both of which showed a high degree of fasciculation. Differences between fasciculation on LAM and PL were noted previously by Hopkins et al. (1985). Soluble Ep and polymerized Ep did not appear to differ in their properties as growth substrates in our assays.

On uncoated glass in most cases ( 37 of 44 cases), no growth occurred at all even after 2-3 days. In the remaining cases, a few short neurites appeared [Fig. 2(B)], but these were often later retracted. When the ependymin was plated in a striped pattern on glass, the axons grew out only on the stripes covered with Ep, and completely avoided the uncoated glass [Fig. I (C)]. At the end of the ependymin stripes, the axons did not advance forward on the glass but they did fasciculate with each other across stripes. The growth cones at the tips of axons growing on ependymin stripes were very active and complex with many filopodia and often a veil of lamellopodia (Fig. 3).

\section{Stripe Assays of Substrates}

When stripes of Ep were plated over a uniform substrate of Con A, the axonal outgrowth was largely random [Fig. 4(A), Table 1]. Ep is known to bind to Con A (Schmidt and Shashoua, 1981). Stripes of Ep over PL also produced generally random outgrowth (Table 1). However, when ependymin stripes were plated over LAM substrate, the

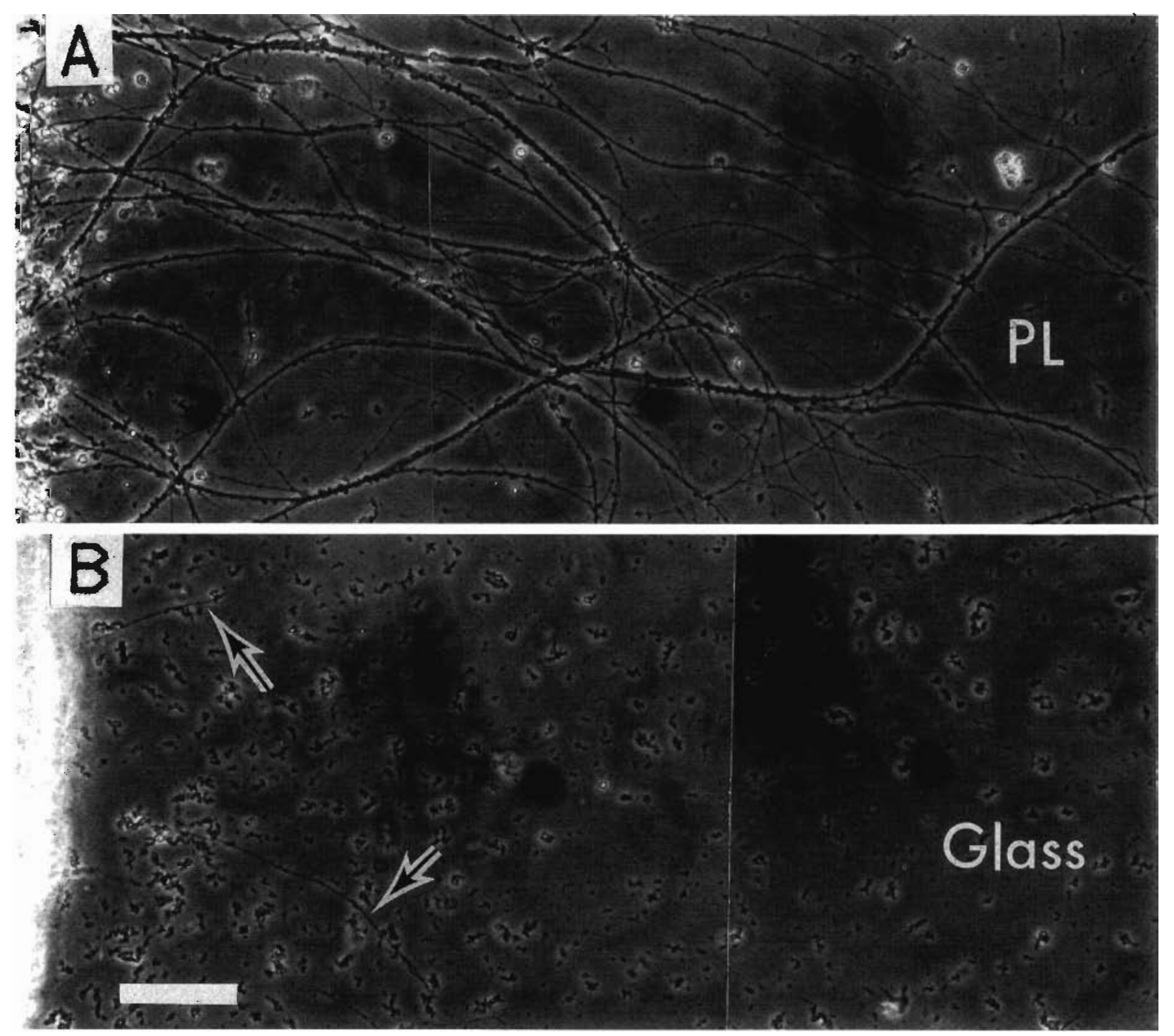

Figure 2 Outgrowth of axons on different substrates at 2.5 days. (A) Uniform polylysine. (B) Uncoated glass. Cultures were viewed with phase optics. Note the extensive fasciculation on polylysine (A) and the scarcity of neurites on uncoated glass. Scale bar $=100 \mu \mathrm{m}$. 


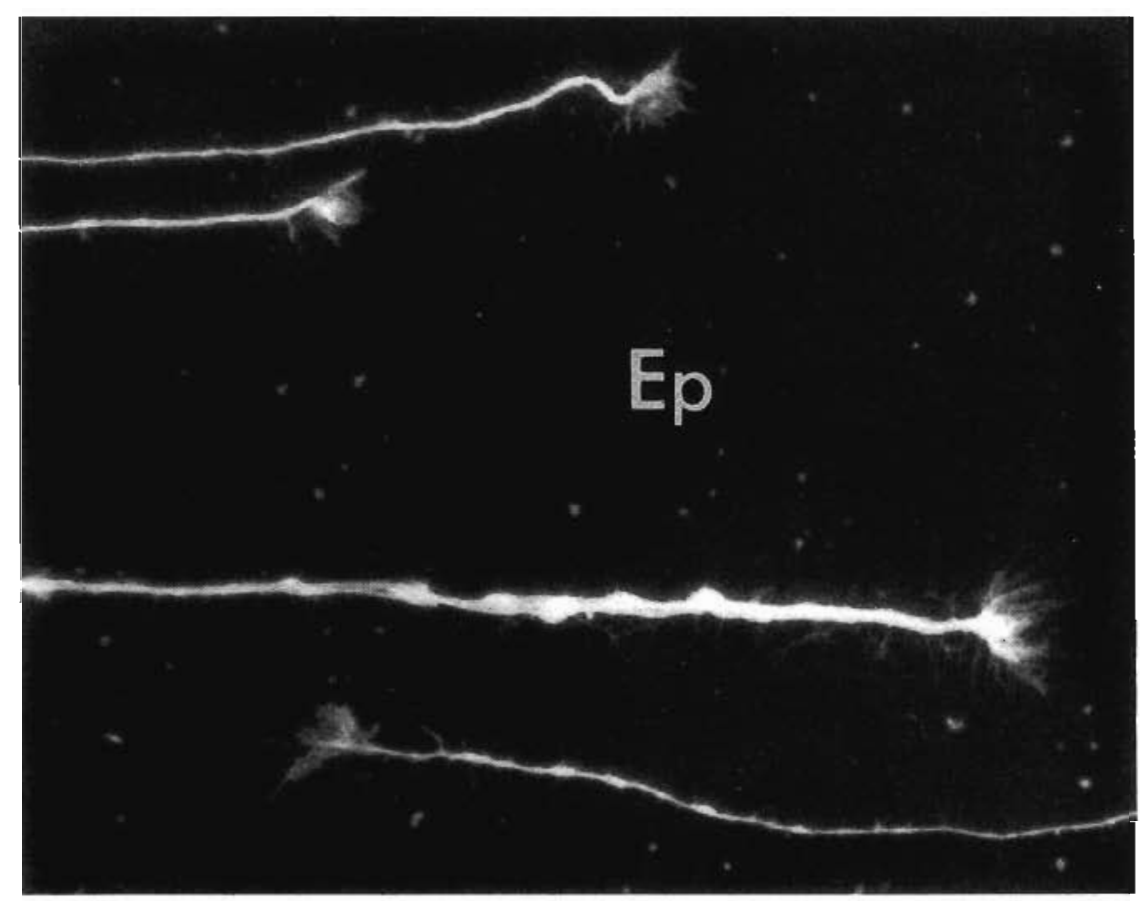

Figure 3 Growth cones growing on stripes of soluble ependymin on glass. One explant was located to the right and another to the left. Note the microspikes emerging along the neurites as well as from the growth cones. The large neurite at the center may be a fascicle of more than one growing neurite, but the others appear to be single growth cones and neurites. Rhodamine optics.

axons tended to grow on the stripes containing both Ep and LAM more so than on the pure LAM [Fig. 4(B,C), Table 1]. When these cultures were stained with antibodies to Ep after fixation in methanol and formaldehyde, the Ep stripes were clearly fluorescent, but the axons growing along them were not [Fig. 4(C)].

When the proteins were plated in exclusive stripes, random outgrowth was observed for Ep versus PL (Table 1). This confirmed our conclusion that the neurites do not show a preference for either of these substrates. However, the axons clearly preferred to grow on LAM stripes rather than on Ep stripes [Fig. 4(D)]. This was always the case ( six of six cases) when the LAM was plated first, but only in half the cases (three of six) when Ep was plated first. In the other three cases, outgrowth was almost random.

\section{Antibody Blocking Experiments}

Because the stripe experiments above suggested that interactions of the growth cones with Ep and LAM may be independent, we further tested this possibility in the following antibody experiments.
First, we showed that antibodies to Ep can block outgrowth on Ep substrates.

We constructed a stripe assay such that the first stripe $(\mathrm{Ep}, 1 \mathrm{mg} / \mathrm{mL})$ was covered with antiEp $(1: 1,1: 4$, or $1: 10)$ and the second stripe $(\mathrm{Ep}, 1$ $\mathrm{mg} / \mathrm{mL}$ ) with normal rabbit serum in the same dilutions. Axons grew almost exclusively on the second stripe where the Ep was not blocked ( 10 cases). This was the case even when the Ep substrate in stripe 2 was made with solutions 10 times more dilute than in stripe 1 [Fig. 5(A)]. As anticipated, antibody dilutions of 1:200 showed only a slight effect, because there was probably too little total antibody in the small ( $100 \mu 1)$ volume inside the matrix to block a significant fraction of the ependymin bound to the glass. [There would be only $0.5 \mu \mathrm{l}$ of antiserum which, at the rate $1 \mu \mathrm{l}$ of antiserum to bind $1.5 \mu \mathrm{g}$ of Ep (Schmidt and Shashoua, 1983), would be insufficient to block the estimated $1 \mu \mathrm{g}$ of Ep on the glass.]

With these experiments it was impossible to reverse the order of the stripes, as the antibody could not be applied second and still have it restricted to the second stripe. However, control experiments without antibody showed that axons would readily grow on stripe 1 when stripe 2 had 20 times less Ep 
and both were covered with normal rabbit serum [three cases, Fig. 5(B)]. These latter experiments show that the growth cones do choose based on the amount of accessible Ep in the substrate, but that the antibody restricted access to the Ep by binding to and covering the Ep. Ependymin must, therefore, be a better substrate than the IgG of the antibody.
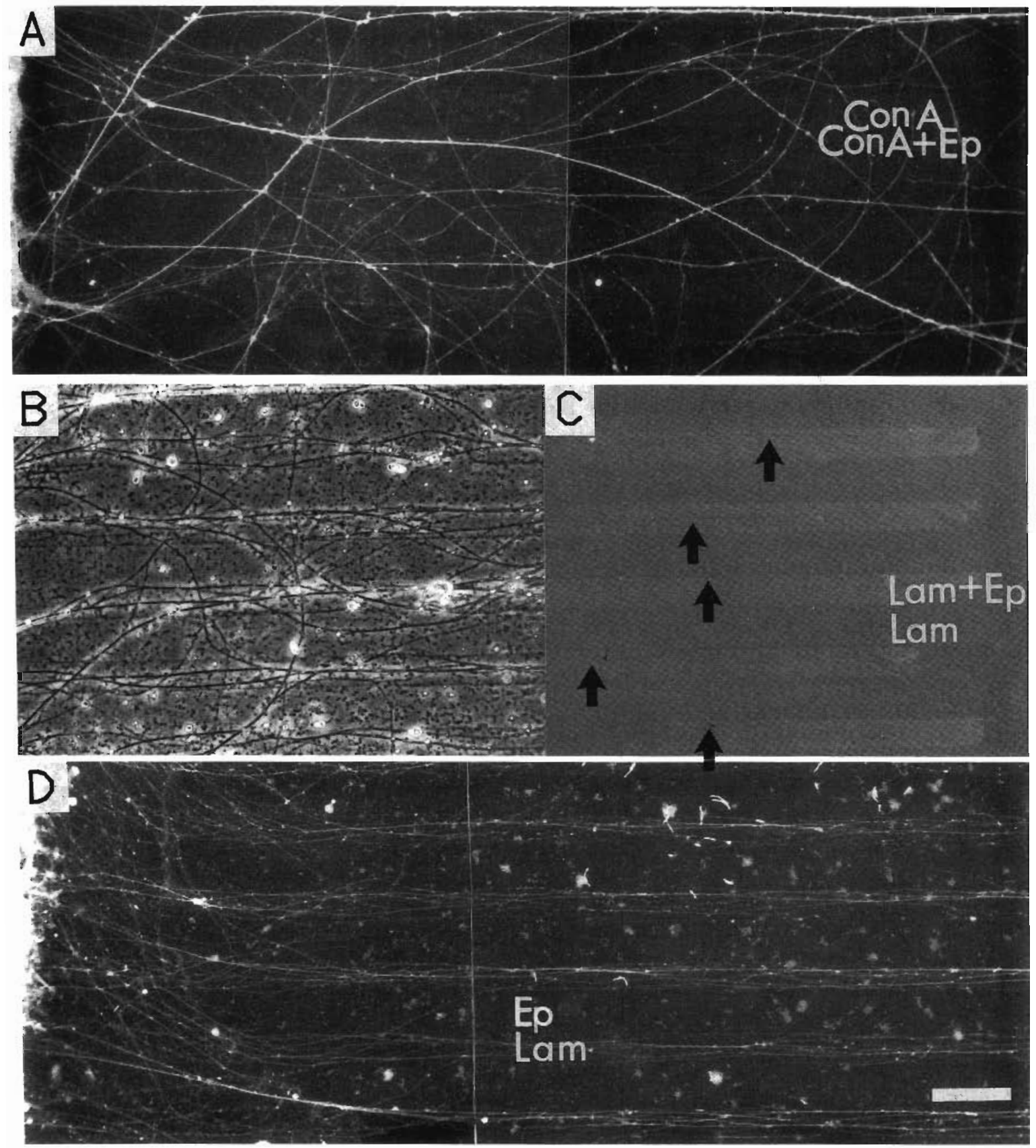

Figure 4 Axons growing in stripe assays after 2 days in culture. (A) Polymerized ependymin stripes over uniform Con A substrate seen with rhodamine staining. (B) Soluble ependymin stripes over uniform laminin substrate seen with phase-contrast optics. (C) Adjacent field of this culture stained with antibody to ependymin and fluorescent second antibody and viewed with fluorescence optics (Olympus, blue excitation). The arrows point to fascicles of axons that can be seen because they do not stain for ependymin although growing on the ependymin plus laminin stripes. (D) Stripe assay with exclusive stripes of ependymin and laminin showing that the axons prefer laminin (rhodamine-staining and optics). Scale bar $=100 \mu \mathrm{m}$. 


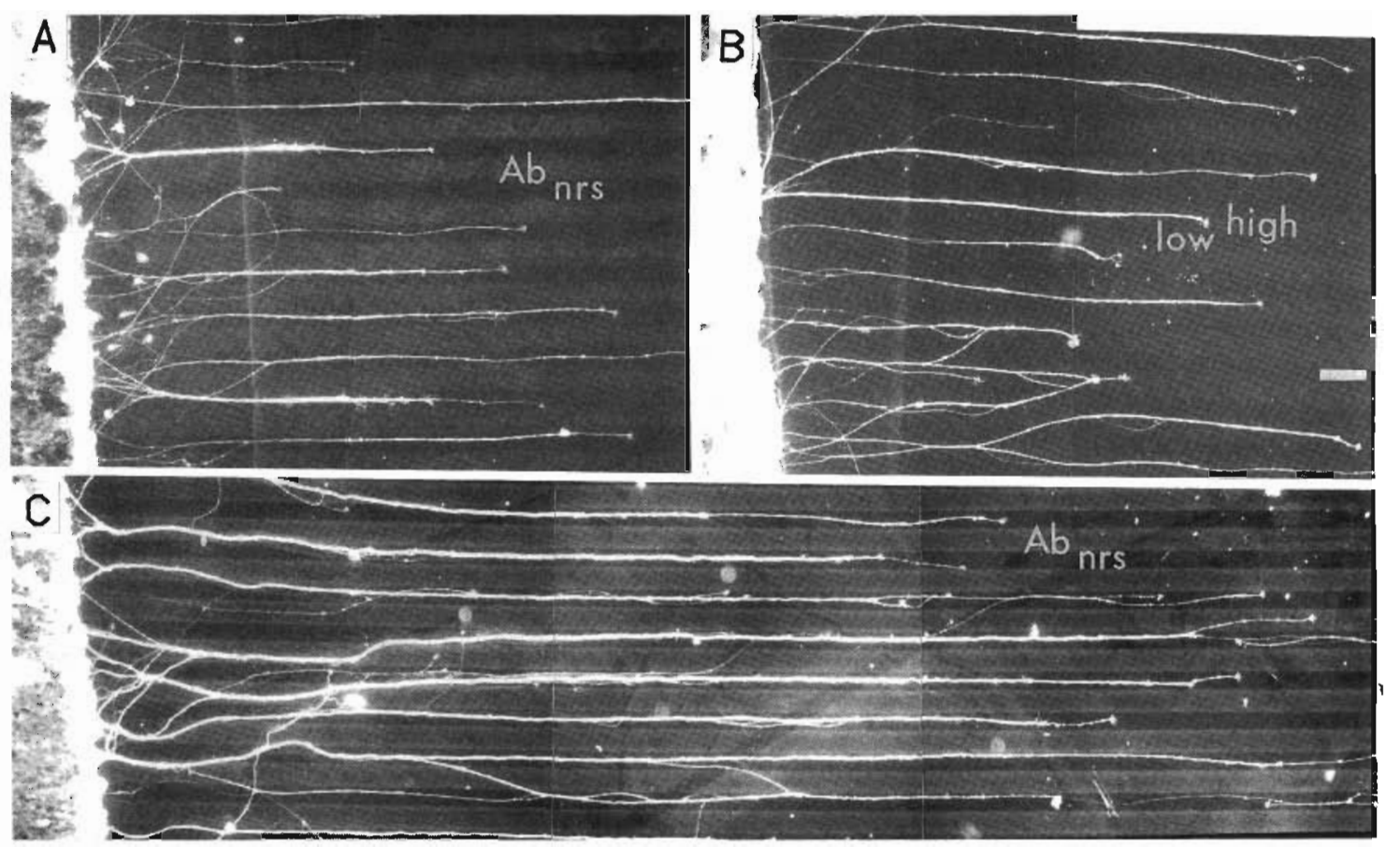

Figure 5 Antibodies to Ep block outgrowth on ependymin. (A) Axons show strong preference to grow on Ep stripe not blocked by antibody even though it was laid down at one-tenth the concentration in the blocked stripe. Stripe 1: Ep at $1 \mathrm{mg} / \mathrm{mL}$, anti Ep at 1:4 dilution, and $\mathrm{Hb}$ FITC at $4 \mathrm{mg} / \mathrm{mL}$; Stripe 2: Ep at $0.1 \mathrm{mg} / \mathrm{mL}$, normal rabbit serum at 1:4 dilution. Note that axons grow on the nonfluorescent stripes (stripe 2). (B) Axons show preference to grow on higher concentration of Ep. Stripe 1: Ep at $1 \mathrm{mg} / \mathrm{mL}$, Hb-FITC at $4 \mathrm{mg} / \mathrm{mL}$; Stripe 2: Ep at $0.05 \mathrm{mg} / \mathrm{mL}, \mathrm{Hb}$ at $4 \mathrm{mg} / \mathrm{mL}$. Note that axons grow on the fluorescent stripe 1. (C) Axons show strong preference to grow on unblocked stripes laid down over a uniform substrate of Ep $(0.1 \mathrm{mg} / \mathrm{mL})$. Stripe 1: antiEp at $1: 4$ dilution, Hb-FITC at $4 \mathrm{mg} / \mathrm{mL}$; Stripe 2: normal rabbit serum at 1:4 dilution. Note that axons show strong preference for the nonfluorescent stripe 2 .

An alternative approach was to plate uniform Ep over the whole coverslip, then use the matrix to apply antiEp in stripe 1 , followed by normal rabbit serum over stripe 2 . In these three cases, there was an extremely marked preference for stripe 2 where the Ep was not blocked [Fig. 5(C)]. These two sets of experiments conclusively show that antibodies to Ep effectively block outgrowth on Ep.

Second, because the strips of retinal tissue might secrete endogenous LAM or Ep into the

Table 1 Results of Stripe Assays of Substrates

\begin{tabular}{|c|c|c|}
\hline Type of Stripes & No. of Cases & Cases with Effect \\
\hline \multicolumn{3}{|c|}{ Ependymin stripes over other substrates } \\
\hline Ep over LAM & 8 & 7 prefer LAM + Ep \\
\hline Ep over Con A & 16 & 16 all random \\
\hline Ep over PL & 4 & 4 no real preference \\
\hline Ep over uncoated glass & 20 & 18 strong preference and 2 weak preference \\
\hline \multicolumn{3}{|l|}{ Exclusive stripes } \\
\hline 1. Ep 2. LAM & 6 & 3 prefer LAM, 3 random \\
\hline 1. LAM 2. Ep & 6 & 6 all prefer LAM \\
\hline 1. Ep 2. PL & 6 & $\begin{array}{l}1 \text { random, } 5 \text { mostly random with slight } \\
\text { preference for } \mathrm{Ep}\end{array}$ \\
\hline 1. PL 2. Ep & 6 & $\begin{array}{l}2 \text { random, } 4 \text { mostly random with slight } \\
\text { preference for } P L\end{array}$ \\
\hline
\end{tabular}


culture medium, we tested the growth of neurites on either substrate in the presence of antibodies to the other. Outgrowth of axons on uniform LAM substrates was not at all retarded by the presence of Ep antibody ( 10 cases; 1:200 dilution and 1:50 dilution) in the medium [Fig. 6(A)]. As this antibody blocks growth on Ep and should, therefore, neutralize any secreted Ep, the result shows that LAM alone is a good substrate. In addition, the neurites grown on LAM did not stain for Ep. In 16 cases where staining for ependymin was attempted in cultures grown on LAM, there was also no staining of the axons or growth cones.

Conversely, outgrowth on Ep was not at all retarded by the presence of LAM antibody in the culture medium (38 cases; 1:100 and 1:200 dilutions). This LAM antibody could block or greatly retard growth on LAM at 1:50 concentration in the medium ( 26 cases), even though an estimated $1 \mu \mathrm{g}$ of LAM was attached to the glass surface. The smaller quantities of antiLAM used here should have neutralized any LAM secreted into the me-
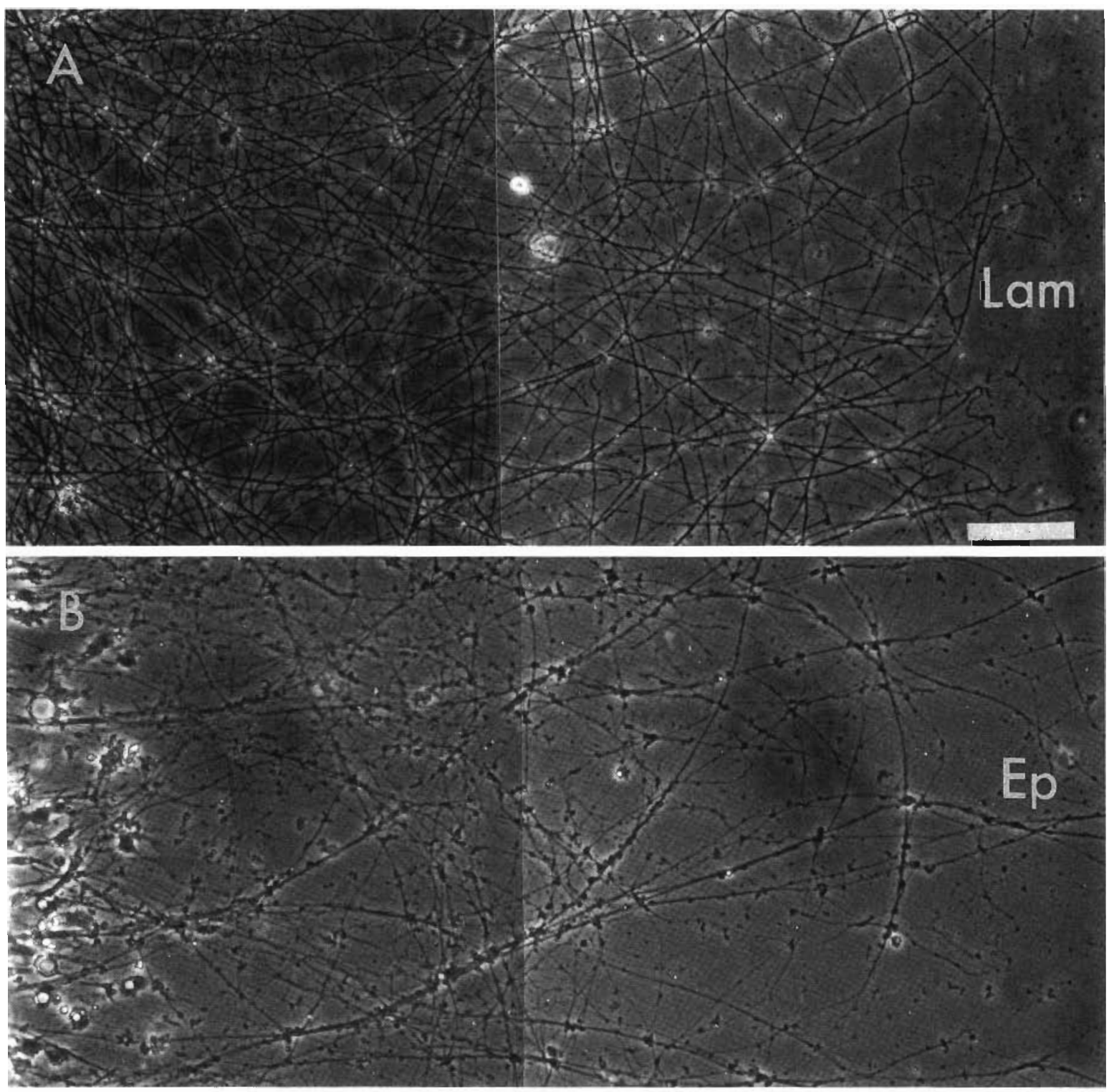

Figure 6 Antibody experiments suggesting independence of growth on Ep and LAM. (A) Neurite outgrowth on uniform laminin substrate is unaffected in the presence of antibody to ependymin (1/200 dilution). (B) Neurite outgrowth on uniform ependymin substrate is unaffected in the presence of antibody to laminin ( $1: 100$ dilution). Both 3 days in culture, phase-contrast optics. Scale bar $=100 \mu \mathrm{m}$ for A and $80 \mu \mathrm{m}$ for B. 
dium. In addition, the degree of fasciculation on Ep was characteristically different from that on LAM and independent of the LAM antibody in the medium [Fig. 6(B)]. In both cross-antibody experiments, the progress of outgrowth, observed during the first day, appeared to be as fast and as widespread as in control sister cultures without antibody, indicating that the antibodies did not slow down outgrowth. These data combined with the clear preferences in the stripe assays above (for a mixture of Ep and LAM over pure LAM, but for pure LAM over pure Ep) suggest that LAM and Ep exert their effects entirely independently.

\section{Immunoblots}

In dot blots [Fig. 7(A)], the Ep antibody showed much stronger recognition of denatured monomer Ep (Ep D) than of native Ep, as expected (Schmidt and Shashoua, 1981). The Ep antibody showed very little, if any, recognition of native LAM, although it did show slight recognition for LAM denatured in SDS gel sample buffer (Lam D). However, there was no recognition of LAM apparent on the western blots [Fig. 7(B)]. Slight cross-reactivity was reported in dot blots by Shashoua, Hesse, and Milinazzo, (1990) who found that a five amino-acid run is common in the sequences of the two molecules. On the dot blots, the regenerating optic nerve (ONR) samples showed substantial staining by the Ep antibody. The amount present in the nerves estimated from these dot blots was about $2 \mu \mathrm{g}$ per mg wet weight. The western blots [Fig. 7(B)] showed that most of this reactivity was in the form of the two Ep monomers at 31 and $37 \mathrm{kD}$, although there was, as previously reported by Shashoua (1988), a smear of staining at higher molecular weights, which probably represents partially polymerized Ep.

The LAM antibody on the dot blots recognized native LAM slightly better than denatured LAM. The LAM antibody showed no recognition of the native Ep but slight recognition of the denatured Ep. The dot blots also showed some LAM immunoreactivity in the regenerating optic nerve samples. The estimated amount appeared to be much less than that for Ep. On western blots, the LAM antibody recognized, as expected, the LAM bands at approximately 200 and $400 \mathrm{kD}$, the $200-\mathrm{kD}$ band being much darker, probably due to its more efficient transfer. In addition, there were several fainter bands at lower molecular weights (marked with dots). In the heavily loaded optic nerve lanes, there was little or no staining corresponding to the main LAM bands, but there was some staining at several lower molecular weight bands when the blot was strongly reacted [Fig. 7(B)]. The uppermost of these bands appeared only in the regenerating nerve and corresponded to one of the faint bands on the LAM lane. It may, therefore, represent a breakdown product of LAM which is thought to be expressed in the regenerating (but not normal) optic nerves (Hopkins, Ford-Holevinski, McCoy, and Agranoff, (1986).

\section{DISCUSSION}

\section{Major Findings}

The major findings of this study are (1) that ependymin is a good substrate for axonal outgrowth, slightly better than Con A and polylysine but not as good as laminin, (2) that growth-cone binding to ependymin appears to be independent of that to laminin because a mixture is preferred to laminin alone, and (3) that antibodies to ependymin can block outgrowth on ependymin but not on laminin.

\section{Ependymin as Substrate}

Ependymin was compared with other substrate proteins in two separate ways: (1) observations of speed and extent of outgrowth on uniform substrates; and (2) tests of preference in side-by-side stripes. The results of the two methods are consistent. Growth on ependymin was only slightly faster than that on Con A and PL, and there was little preference between them in side-by-side exclusive stripes or in Ep stripes over the other substrates. In addition, outgrowth on Ep was less than half as fast as on pure LAM substrates, and LAM was preferred to Ep in exclusive side-by-side stripes. Fibronectin was not used in these comparisons because retinal neurites do not grow on it (Rogers, Letorneau, Palm, McCarthy, and Furcht, 1983; Hopkins et al., 1985).

\section{Validity of the Stripe Assay}

The validity was demonstrated in previous papers (Vielmetter et al., 1986 and submitted). First, the validity can be seen in that the same preference is registered when the order of the proteins in the two stripes is reversed. Second, no preference (and lots of crossing) is seen when the same protein is in both stripes, thereby ruling out mechanical effects at the boundary. Reversal of the protein stripes here in the case of exclusive LAM and Ep stripes, 

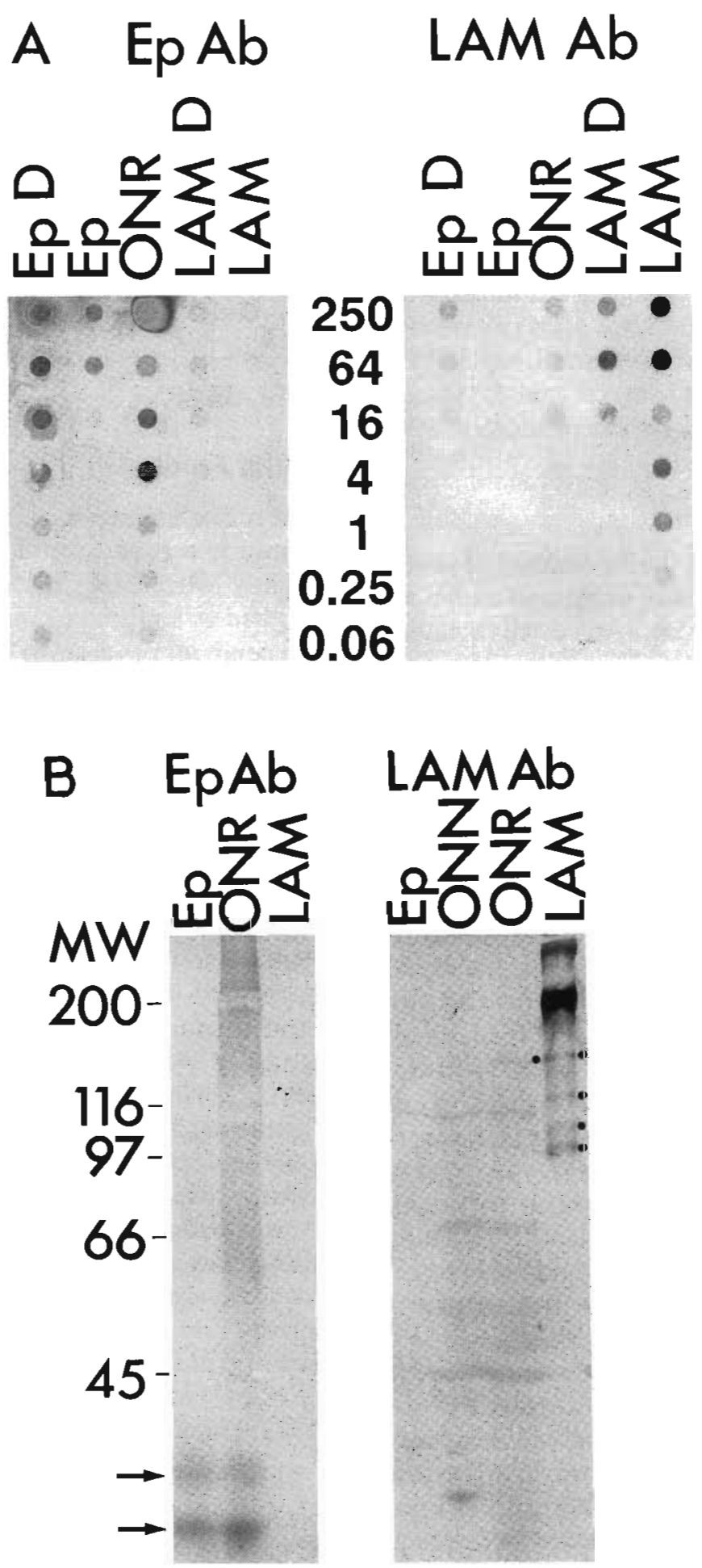

Figure 7 Dot blots (A) and western blots (B) with Ep and LAM antibodies. (A) The dots on nitrocellulose paper were made with Ep denatured and reduced in sample buffer (Ep D), native purified Ep, regenerating optic nerve solubilized in sample buffer (ONR), LAM denatured and reduced in sample buffer (LAM D) and native LAM. The nanogram quantities refer to the Ep and LAM samples. For the optic nerve sample, two nerves weighing about $5 \mathrm{mg}$ total were solubilized in $150 \mu \mathrm{l}$ sample buffer, and $2.5 \mu \mathrm{l}$ was loaded onto the first dot with four times the dilutions thereafter. Antibody concentrations were 1:500 for both antiEp and antiLAM. (B) Western blots of $7.5 \%$ reducing SDS-PAGE transferred to nitrocellulose paper. 
also showed the same preferences, although the effect was stronger when LAM was plated first. The exclusivity of the stripes was ensured by the saturation of binding sites within the first stripe with the highly concentrated hemoglobin solution. Fluorescent antibody staining here showed that the first stripes were sharp.

Time lapse studies show that growth cones encountering a boundary from the preferred substrate side are generally reflected. Those approaching from the nonpreferred side cross over and elongate further on the preferred substrate ( $F$. Bonhoeffer, unpublished observations; Stuermer, 1989). Once on the preferred substrate, the growth cones repeatedly make contacts with the boundary of the non-preferred substrate, but they do not recross. Thus, the growth cone's ability to discriminate between the two substrates results in the accumulation of axons only on the preferred substrate stripe.

\section{Relation to Laminin Binding}

The binding of the growth cones to ependymin appears to be independent from that to laminin for two reasons. First, the antibody experiments showed that outgrowth on laminin was not blocked or slowed by antibodies to ependymin, nor was outgrowth on ependymin slowed by antibodies to laminin, even though both antibodies could block outgrowth on their corresponding proteins. Second, although pure laminin was preferred to pure ependymin stripes, the mixture of laminin and ependymin was, in fact, preferred to pure laminin. This would be expected if the effects of the two were additive. This better response to the two together is interesting as laminin is thought to be expressed by astrocytes during optic nerve regeneration in goldfish (Hopkins et al., 1985). The dot and western blots offered suggestive support for this idea, but we were not able to stain definite LAM bands at 200 and $400 \mathrm{kD}$ even with heavy loading of the gel. This could be due to the small amounts present and the inefficient transfer of these high molecular weight components on western blots.
Shashoua, Daniel, Moore, and Jungalwala, (1986) found that ependymin contains the carbohydrate epitope recognized by the HNK-1 monoclonal antibody. Recently, when the gene for the ependymin precursor was successfully cloned (Koenigstorfer et al., 1989), the sequence showed two possible $N$-glycosylation sites. HNK-1 epitopes are typical for molecules involved in cell-cell interactions, appearing, for example, on several neural-cell adhesion molecules and on myelin-associated glycoproteins (Kruse et al., 1985). Although it is not yet established whether ependymin serves as a substrate for axons in vivo, several lines of evidence are consistent with this idea. First, ependymin is present in insoluble matrix form in goldfish brain (Shashoua et al., 1989). Second, ependymins were shown to be present in optic nerve by immunoblots (this study) and specifically in astrocytes of the nerve by immunohistochemical staining (J. Schmidt, R. Schmidt, S. Rother and M. Bastmeyer, unpublished observations). Third, such glial cells in culture are highly permissive for the growth of retinal axons (Bastmeyer et al., 1989; Stuermer, unpublished observations).

\section{Role of Ependymin in Synaptic Growth and Stabilization}

Learning triggers protein synthesis (Shashoua, 1976, 1985; Schmidt, 1987, 1989; Shashoua and Hesse, 1989; Duffy, Teyler, and Shashoua, 1981; Fazeli, Errington, Dolphin, and Bliss, 1988), and memory consolidation depends upon protein synthesis (Flexner et al., 1963; Goelet et al., 1986). Ependymin is one of the proteins synthesized (Shashoua, 1976; Fazeli et al., 1988). Antibodies to ependymin, in addition to blocking memory consolidation, also block sharpening of the retinotectal map (Schmidt and Shashoua, 1988), a process that is known to involve restructuring of retinal terminals (Schmidt, Turcotte, Buzzard, and Tieman, 1988; Schmidt and Buzzard, 1990). These two processes, linked in requiring specific converging patterns of activity, are now linked by ependymin involvement. At present, it is not

Biotinylated high molecular weight standards were run in lanes alongside. LAM lanes were loaded with $4 \mu \mathrm{g}$ of protein. Ep lanes were loaded with $4 \mu \mathrm{g}$ for the antiLAM blot but only 0.5 $\mu \mathrm{g}$ for the antiEp blot. Optic nerve lanes were loaded with $16 \mu \mathrm{l}$ and $25 \mu \mathrm{l}$ of the $150 \mu \mathrm{l}$ total sample above for the Ep and LAM Ab blots. Arrows mark the ependymin monomers at approximately 31 and $37 \mathrm{kD}$. Dots to the right of bands mark possible breakdown products of the main LAM bands at 200 and $400 \mathrm{kD}$. 
known how antiependymin prevents the rearrangements of axonal terminals that underly sharpening, but the present results, that ependymin substrates promote growth and that antiependymin blocks this growth-promoting interaction, may help to understand this process.

Shashoua (1985) advanced a speculative model based upon the finding that ependymin polymerizes in low-calcium media (Shashoua, 1985, 1988), and may, therefore, be selectively deposited at highly active convergent synapses. Strong synaptic activity can lower the extracellular calcium concentration (Krnjevic et al., 1982; Marciani et al., 1982; Morris et al., 1988) because of calcium influx through NMDA ( $N$-methyl-D-aspartate) receptors at participating synapses (MacDermott, Mayer, Westbrook, Smith, and Barker, 1986). In area $\mathrm{CA} 1$ of the hippocampus, such activation, which triggers long-term potentiation, also triggers ependymin polymerization (Shashoua and Hesse, 1985). The deposition of an ependymin matrix at participating synapses could promote the selective growth of these coactive synapses onto each cell.

The idea that extracellular matrix components may influence the formation of synaptic structures is supported by observations on the neuromuscular junction where regenerating motor axons form presynaptic terminals at synaptic sites on empty basal laminae and where regenerating muscle fibers form postsynaptic specializations at such sites in the absence of the motor terminal (Sanes, 1983). Extracellular matrices are not usually present between neurons in brain, but ependymin, with its triggered polymerization from a soluble form that is always present in the ECF, could serve a similar role in promoting synaptic growth. At the neuromuscular junction, the regenerating nerve stops and elaborates a nerve terminal at the previous site. In the visual system, the sharpening of the retinotopic map, like most synapse elimination phenomena, is more dynamic requiring coincident inputs to stimulate the growth of new branches and contacts as well as retraction of errant branches (Schmidt et al., 1988; Schmidt and Buzzard, 1990). Retinal terminals are also known to enlarge as they mature (Mason, 1982; Stuermer and Easter, 1984), so that considerable growth of both branches and terminals must occur. Likewise in several models of long-term memory, there seems to be considerable growth of new synapses or enlargement of existing synapses (Bailey and Chen, 1988; Greenough and Bailey, 1988).

The finding in this study that antibody binding to ependymin blocks its potency as a growth substrate suggests that the antibody might act either to prevent growth of synapses over this matrix or to prevent the addition of polymerized deposits. This antibody, as well as similarly generated antibodies to Ep, is known to bind to the polymerized form and to the monomers but to be poorly reactive to the native soluble dimers (Schmidt and Shashoua, 1981; Shashoua, 1985, 1988). The antibodies do not interfere with synaptic transmission (Schmidt and Shashoua, 1988) or induction of long-term potentiation (LTP) (Seifert, Terlau, and Schmidt, 1988). We saw no difference between results with soluble and polymerized ependymin, but there was undoubtedly soluble ependymin in the polymerized samples and, in addition, the soluble ependymin becomes immobilized onto a glass surface, which may be the function of polymerization when it occurs in vivo.

This work was supported by NIH grant EY-03736 to J.T.S., by a Deutsche Forschungsgemeinschaft (DFG) grant Schm 478/4-3 to R.S., and by grants from the Max-Planck-Gesellschaft (MPG) and DFG to C.A.O.S. We would like to thank Friedrich Bonhoeffer for generously providing the matrix, and Anette Habring and Marlene Buzzard for technical assistance, Martin Bastmeyer for photography, and Jost Vielmetter for advice on use of the stripe assay.

\section{REFERENCES}

BAILEy, C. and CHEN, M. (1988). Long-term memory in Aplysia modulates the total number of varicosities of single identified sensory neurons. PNASUSA 85:2373-2377

Bastmeyer, M., Beckmann, M., Nona, S. M., Cronly-Dillon, J. R., and Stuermer, C. A. O. (1989). Identification of astrocyte- and oligodendrocyte-like cells of goldfish optic nerves in culture. Neurosci. Lett. 101:127-132.

Benowitz, L. I. and Shashoua, V. E. (1977). Localization of a brain protein metabolically linked with behavioral plasticity in the goldfish. Brain Res. 136:227-242.

DufFy, C., Teyler, T. J., and Shashoua, V. E. (1981). Long-term potentiation in the hippocampal slice: Evidence for stimulated secretion of newly synthesized proteins. Science 212: 1 148-1151.

FAZELI, M. S., ERRINGTON, M. L., DOLPHIN, A. C., and BLISS, T. V. P. (1988). Long-term potentiation in the dentate gyrus of the anaesthetized rat is accompanied by an increase in protein efflux into push-pull cannula perfusates. Brain Res. 473:51-59.

Flexner, J. B., Flexner, L. B., and Stellar, E. (1963). Memory in mice is affected by intracerebral puromycin. Science 141:57-59.

Goelet, P., Castellucci, V. F., Schacher, S., and KANDEL, E. R. (1986). The long and the short of 
long-term memory-a molecular framework. Nature 322:419-422.

Greenough, W. T. and Balley, C. H. (1988). The anatomy of a memory: convergent results across a diversity of tests. Trends Neurosci. 11:142-147.

Hopkins, J. M., Ford-Holevinski, T. S., MCCOy, J. P., and AgranofF, B. W. (1985). Laminin and optic nerve regeneration in goldfish. J. Neurosci. 5:3030-3038.

Koenigstorfer, A., Sterrer, S., Eckerskorn, C., LOTTSPEICH, F., SCHMIDT, R., and HOFFMAN, W. (1989). Molecular characterization of an ependymin precursor from goldfish brain. J. Neurochem. 52:310-312.

KrnjeVic, K., Morris, M. E., and Reiffenstein, R. J. (1982). Stimulation evoked changes in extracellular $\mathrm{K}^{+}$and $\mathrm{Ca}^{2+}$ in pyramidal layers of the rat's hippocampus. Can. J. Physiol. Pharmacol. 60:1643-1657.

Kruse, J., Mailhammer, R., Wernicke, H., Faissner, A., Sommer, I., Goridis, C., and SCHACHNER, M. (1985). Neural cell adhesion molecules and myelin-associated glycoprotein share a common carbohydrate moiety recognized by monoclonal antibodies L2 and HNK-1. Nature 311:153155.

LAEMMLI, U. K. (1970). Cleavage of structural proteins during the assembly of the head of bacteriophage T4. Nature 227:680-685.

MacDermott, A. B., Mayer, M. L., Westbrook, G. L., Smith, S. J., and Barker, J. L: (1986). NMDA receptor activation increases cytoplasmic calcium concentration in cultured spinal cord neurons. Nature 321:519-522.

Marciani, M. G., Louvel, J., and Heinemann, U. (1982). Aspartate induced changes in extracellular free calcium in "in vitro" hippocampal slices of rats. Brain Res. 238:272-277.

MaSOn, C. A. (1982). Development of terminal arbors of retino-geniculate axons in the kitten-II. Electron microscopical observations. Neuroscience 7:561-582.

MCKenNA, M. P. and RAPER, J. A. (1988). Growth cone behavior on substratum-bound laminin. Dev. Biol. 130:232-236.

Montarolo, P. G., Goelet, P., Castellucci, V. F., Morgan, J., Kandel, E. R., and SCHacher, S. (1986). A critical period for macromolecular synthesis in long-term heterosynaptic facilitation in Aplysia. Science 234: 1249-1254.

MORris, M. E., Ropert, N., and Shashoua, V. E. (1988). Stimulus-evoked changes in extracellular calcium in optic tectum of the goldfish: possible role in neuroplasticity. Ann. N.Y. Acad. Sci. 481:375-377.

Piront, M.-L. and SCHMidT, R. (1988). Inhibition of long-term memory formation by anti-ependymin antisera after active shock-avoidance learning in goldfish. Brain Res. 442:53-62.

Rogers, S. L., Letourneau, P. C., Palm, S. L., MCCARTHY, J., and FurChT, L. T. (1983). Neurite extension by peripheral and central nervous system neurons in response to substratum-bound fibronectin and laminin. Dev. Biol. 98:212-220.

SANES, J. ( 1983). Roles of extracellular matrix in neural development. Annu. Rev. Physiol. 45:581-600.

SCHMIDT, J. T. and Buzzard, M. (1990). Activity dependent sharpening of the regenerating retinotectal projection: effects of blocking activity and of strobe synchronizing activity on individual regenerating arbors stained with HRP. J. Neurobiol. 21:900-917.

Schmidt, J. T. and Shashoua, V. E. (1988). Antibodies to ependymin block the sharpening of the regenerating retinotectal projection in goldfish. Brain Res. 446:269-284.

SChmidt, J. T., TurcotTe, J. C., Buzzard, M., and TIEMAN, D. G. (1988). Staining of regenerated optic arbors in goldfish tectum: Progressive changes in immature arbors and a comparison of mature regenerated arbors with normal arbors. J. Comp. Neurol. 269:565-591.

SCHMIDT, R. (1983). Long-term memory and morphological distribution of involved proteins in goldfish brain. Verh. Anat. Ges. 77:725-726.

SCHMIDT, R. (1986). Biochemical participation of glycoproteins in memory consolidation after two different training paradigms in goldfish. In: Learning and Memory: Mechanisms of Information Storage in the Nervous System. Advances in the Biosciences Vol. 59. H. Matthies, Ed., Pergammon Press, Oxford, pp. 213-222.

SCHMIDT, R. (1987). Changes in subcellular distribution of ependymins in goldfish brain induced by learning. J. Neurochem. 48:1870-1878.

SCHMidT, R. (1989). Glycoproteins involved in longlasting plasticity in the teleost brain. In: Fundamentals of Memory Formation: Neural Plasticity and Brain Function. Progr. Zool., Vol. 37. H. Rahmann, Ed., Gustav Fischer Verlag, Stuttgart, New York, pp. 327-339.

SCHMidT, R., LOEFFler, F., Mueller, H. W., and SEIFERT, W. (1986). Immunological cross-reactivity of cultured rat hippocampal neurons with goldfish brain proteins synthesized during memory consolidation. Brain Res. 386:245-257.

SCHMIDT, R., ROTHER, S., and SCHWERDTFEGER, W. K. (In press). Glycoproteins of the extracellular matrix mediate plasticity in the CNS. In: Structure and Development of the Forebrain in Lower Vertebrates. W. K. Schwerdtfeger and P. Germroth, Eds., Springer Verlag, Berlin and Heidelberg.

SCHMIDT, R. and SHaShoua, V. E. (1981). A radioimmunoassay for ependymins beta and gamma: Two goldfish brain proteins involved in behavioral plasticity. J. Neurochem. 36:1368-1377.

SCHMidT, R. and Shashoua, V. E. (1983). Structural and metabolic relationships between goldfish brain glycoproteins participating in functional plasticity of the central nervous system. J. Neurochem. 40:652660.

Seifert, W., Terlau, H., and Schmidt, R. (1988). A possible role for ependymin in hippocampal plastic- 
ity. In: Modulation of Synaptic Transmission and Plasticity in Nervous Systems, NATO-ASI Series Vol. H19. G. Hertting and H.-C. Spatz, Eds., SpringerVerlag, Berlin/Heidelberg, pp. 249-257.

ShashouA, V. E. (1976). Brain metabolism and the acquisition of new behaviors. I. Evidence for specific changes in the pattern of protein synthesis. Brain Res. 111:347-364.

ShashouA, V. E. (1985). The role of brain extracellular proteins in neuroplasticity and learning. Cell. Mol. Neurobiol. 5: 183-207.

Shashoua, V. E. (1988). Monomeric and polymeric forms of ependymin: A brain extracellular glycoprotein implicated in memory consolidation processes. Neurochem. Res. 13:649-655.

Shashoua, V. E., Daniel, P. F., Moore, M. E., and Jungalwala, F. B. (1986). Demonstration of glucuronic acid on brain glycoproteins which react with HNK-1 antibody. Biochem. Biophys. Res. Comm. 138:902-909.

Shashoua, V. E. and Hesse, G. ( 1985). Role of brain extracellular proteins in the mechanism of long-term potentiation in rat brain hippocampus. Neurosci. Abstr. 11:782.

Shashoua, V. E. and Hesse, G. (1989). Classical conditioning leads to changes in extracellular concentrations of ependymin in goldfish brain. Brain Res. 484:333-339.

Shashoua, V. E., Hesse, G. W., and Milinazzo, B. (1990). Evidence for the in vivo polymerization of ependymin: A brain extracellular glycoprotein. Brain Res. 522:181-190.

Shashoua, V. E. and Holmquist, B. (1986). Extra- cellular fluid proteins of goldfish brain: Evidence for the presence of proteases and esterases. J. Neurochem. 47:738-743.

Shashoua, V. E. and Moore, M. E. (1978). Effect of antisera to beta and gamma goldfish brain proteins on the retention of a newly acquired behavior. Brain Res. 148:441-449.

Stuermer, C. A. O. (1989). Dynamics of axonal growth and target recognition in the retinotectal system of fish. In: Dynamics and Plasticity of Neuronal Systems. N. Elsner and W. Singer, Eds., Thieme Press, Stuttgart/New York, pp. 87-92.

Stuermer, C. A. O. and EASTER, S. S. (1984). A comparison of the normal and regenerated retinotectal pathways of goldfish. J. Comp. Neurol. 223:57-76.

Towbin, H., Staehelin, T., and Gordon, J. (1979). Electrophoretic transfer of proteins from polyacrylamide gels to nitrocellulose sheets: Procedure and some applications. PNASUSA 76:4350-4364. ,

Vielmetter, J., Stolze, B., Henke-Fahle, S., STUERMER, C: A. O., and BONHOEFFER, F. (1986). In vitro assay to test the differential substrate affinity of growing axons. Neurosci. Lett. [Suppl.] 26:167171 .

Vielmetter, J. and Stuermer, C. A. O. (1989). Goldfish retinal axons respond to position-specific properties of tectal cell membranes in vitro. Neuron 2:1331-1339.

Walter, J., Kern-Veits, B., Huf, J., Stolze, B., and BONHOEFFER, F. ( 1987). Recognition of positionspecific properties of tectal cell membranes by retinal axons in vitro. Development 101:685-696. 